\title{
Biodegradation of animal fats and vegetable oils by Rhodococcus erythropolis PR4
}

\author{
Ágnes Kis a, b, c, Krisztián Laczi a , Szilvia Zsíros a , Gábor Rákhely a, b, c, *, Katalin Perei a \\ ${ }^{a}$ Department of Biotechnology, University of Szeged, Közép fasor 52, H-6726 Szeged, Hungary \\ ${ }^{\mathrm{b}}$ Institute of Envirommental Sciences, University of Szeged, Rerrich Béla tér 1, H-6720 Szeged, Hungary \\ ${ }^{c}$ Institute of Biophysics, Biological Research Centre Hungarian Academy of Sciences, Temesvári krt. 62., H-6726 Szeged, Hungary
}

\section{A R T I C L E I N F O}

\section{Article history:}

Received 1 November 2014

Received in revised form

21 July 2015

Accepted 22 August 2015

Available online $\mathrm{xxx}$

\section{Keywords:}

Animal fats

Biodegradation

Fatty acids

Lipase

Rhodococcus erythropolis

Vegetable oil

\begin{abstract}
A B S T R A C T
The alkane (pristane) degradation capacity of Rhodococcus erythropolis PR4 (NBRC 100887), isolated from marine environment, was previously observed. In this study, the ability of this strain for biodegradation of various animal fats, such as pig lards and poultry fats as well as butter, margarine and sunflower cooking oil was studied. Bioconversion of fats and oil was determined as methyl-ester (FAME) derivatives by GC-MS. R. erythropolis PR4 strain could utilize all substrates tested but the bioconversion rate and efficacies varied. The optimum $\mathrm{pH}$ for decomposition of pig lard and poultry fat was 8.5 , respectively. Addition of carbonate to the media dramatically improved the efficiency of the process via stabilization of $\mathrm{pH}$ of the fermentation. Biotransformation of poultry fat was complete in four days and around $80 \%$ conversion was reached in the case of pig lard in media containing carbonate. The extracellular lipase activity of the R. erythropolis PR4 strain was also demonstrated by various techniques. The results suggest the $R$. erythropolis PR4 strain studied is a promising candidate in bioremediation/bioconversion of fatcontaining wastes within a relatively short time.
\end{abstract}

๑ 2015 Elsevier Ltd. All rights reserved.

\section{Introduction}

Among the organic fraction of industrial and municipal wastes, hydrophobic compounds cause outstanding problems. These hydrophobic pollutants, such as diesel oils, animal fats, oils and greases (FOG) are produced by the energy sector, food industry, restaurants, slaughter houses, kitchens (Wakelin and Forster, 1997; Lefebvre et al., 1998; Mari et al., 2003; Saatci et al., 2003). Fats cool down in the gutter, attach to other ingredients of sewage and form hard, soap-like deposits, that create blockages in sewage systems (He et al., 2011, 2012; 2013). In addition, the hydrophobic materials form a layer on the surface of water that blocks oxygenation (Becker et al., 1999; Chipasa and Mędrzycka, 2006; Cipinyte et al., 2009).

Hydrophobic materials are chemically diverse. Diesel oil is composed of both saturated and aromatic hydrocarbons. Many lipids consist of various fatty acids and a glycerol moiety. The fatty acid compositions of a given lipid strongly depend on its origin. Bitman (1976) demonstrated that pig lard contains oleic acid in a

\footnotetext{
* Corresponding author. Department of Biotechnology. University of Szeged, Közép fasor 52, H-6726 Szeged, Hungary.

E-mail address: rakhely@brc.hu (G. Rákhely).
}

large percentage (47\%), palmitic acid (25\%) and also contains stearic acid (14\%), linoleic acid ( $8 \%)$, palmitoleic acid ( $3 \%$ ) and myristic acid (1\%). Poultry fat contains fewer unsaturated fatty acids such as oleic acid (43\%), but more linoleic acid (18\%), palmitoleic acid (7\%) and also contains palmitic acid (25\%) stearic acid (4\%) and myristic acid (1\%). Butter, margarine and sunflower oil contain mainly glycerolesters composed of saturated and unsaturated fatty acid in various ratios (USDA database, http://ndb.nal.usda.gov/ndb/ nutrients/index). The different proportion of saturated and unsaturated fatty acids in the animal fats can influence how oils are utilized by microorganisms.

Few Rhodococcus species were described as promising hydrocarbon degraders (De Carvalho and Da Fonseca, 2005a, 2005b) which could solubilize and oxidize water insoluble hydrocarbons (Bell et al., 1998; De Carvalho and Da Fonseca, 2005b; Lee et al., 2010). Several bacteria isolated from the environment were documented to be effective for treatment of waste waters containing FOG (Wakelin and Forster, 1998; Keenan and Sabelnikov, 2000; Mongkolthanaruk and Dharmsthiti, 2002; Sugimori et al., 2002; Prasad and Manjunath, 2011; Affandi et al., 2014). Most of these microorganisms (pseudomonads, bacilli) were able to secrete extracellular lipases being essential for biodegradation of lipids 
(Pandey et al., 1999; Jaeger and Eggert, 2002; Serikovna et al., 2013). As an initial step of bioconversion, microbial lipases hydrolyze the ester bonds of glycerol-esters for removing the fatty acids from the glycerol moiety. Next, the fatty acids are converted into acetyl-CoA via $\beta$-oxidation pathway (Tan and Gill, 1985; Ruggieri et al., 2008). However, the microbial degradation of fats is slow due to the limited availability of these hydrophobic materials for microorganisms (Fukase et al., 1993; Lefebvre et al., 1998).

The genera Mycobacterium, Corynebacterium, Nocardia, Rhodococcus can synthesize several types of surfactants (Banat et al., 2010). Some of these surfactants reduce the surface tension of the hydrophobic compounds and so-called micro-droplets (micelles) accessible for the microbes are formed (Fukase et al., 1993; Banat et al., 2010). Another way to access FOG is to modify the cell wall to be endowed by hydrophobic feature.

The use of Rhodococci (Bell et al., 1998) in a broad variety of biotechnological applications is rapidly and steadily increasing. Rhodococcus erythropolis PR4 (NBRC 100887) is a marine bacterium capable to degrade several alkanes (Komukai-Nakamura et al., 1996; Sekine et al., 2006) like pristane (Urai et al., 2007a, 2007b). $R$. erythropolis PR4 (shortly PR4) can produce extracellular polysaccharides that are responsible for emulsification of the hydrophobic substrates (Urai et al., 2007a, 2007b; Hamada et al., 2008). A comparative analysis by Hamada et al. (2008) presented that the PR4 cells possessed a highly hydrophobic cell surface. The genome of the strain has been completely sequenced (Sekine et al., 2006; GenBank ID: GCA_000010105.1) and a number of lipase genes were annotated: 4 codes for triacyl-glycerol lipases and one for monoacyl-glycerol lipase, the others were annotated as lipase.

Although, a number of studies were published about degradation of hydrocarbons by rhodococci, very little is known about the ability of this strain to decompose animal fats and similar wastes. There are a number of publications for FOG biodegradation using pure strains (Tan and Gill, 1985; Sugimori et al., 2002; Prasad and Manjunath, 2011; Affandi et al., 2014) or consortium (Wakelin and Forster, 1998; Keenan and Sabelnikov, 2000; Mongkolthanaruk and Dharmsthiti, 2002). In a recent review (Prasad and Manjunath, 2011), the fat degradation abilities of six lipase producing strains (none of them belonged to Actinobacteria) were compared and showed that the lipid content of the wastes could be practically removed within 12 days.

The objective of this work is to establish an efficient biological treatment for various hydrophobic wastes using a Rhodococcus strain having promising biotechnological potential.

\section{Materials and methods}

\subsection{Chemicals, materials}

Chemicals (chloroform, sulfuric acid, methanol) used for analytical methods were reagent grade and they were purchased from standard commercial suppliers (Reanal, VWR, Merck, Sigma-Aldrich).

Pig lard and poultry fats are shop traded products (Hungary). According to a nutrient database (USDA database, http://ndb.nal. usda.gov/ndb/nutrients/index), pig lard typically contains around $40 \%$ of saturated (palmitic acid, $25-27 \%, 12-14 \%$ stearic acid) and $60 \%$ of unsaturated (44-47\% oleic acid, $8-10 \%$ linoleic acid, $3-4 \%$ palmitoleic acid). The typical fatty acid composition of poultry fat is: $29 \%$ saturated (palmitic acid, $22-25 \%, 4-6 \%$ stearic acid), $65 \%$ unsaturated (37-43\% oleic acid, $16-20 \%$ linoleic acid, $6-8 \%$ palmitoleic acid) fatty acids and $6 \%$ other components. The fatty acids present in our samples were analyzed by GC-MS technique (see 2.4 .2 section) and the major components (palmitic acid, stearic acid, oleic acid, linoleic acid and palmitoleic acid) could be identified. The peaks of oleic acid and linoleic acids notably overlapped therefore they could be qualitatively but not quantitatively separated. The ratio of the fatty acids in pig lard and poultry fat coincided with the data of the USDA database. Butter was a "Hungarian butter" produced by Alfold Tej Ltd and had $82 \%$ $\left(\mathrm{m} \mathrm{m}^{-1}\right)$ of fat content. The ratio of saturated and unsaturated fatty acids in butter was around 2:1 (Alfold Tej Ltd). Rama margarine derived from Unilever Ltd contained $70 \mathrm{~g}$ fats in $100 \mathrm{~g}$ margarine ( $33 \mathrm{~g}$ with saturated, $37 \mathrm{~g}$ with unsaturated fatty acids) (Univer Ltd). Venusz sunflower oil was the product of Bunge Corp, Hungary. In this vegetable oil, the ratio of the fatty acids containing 0,1 or multiple double bounds was approximately 1:2:5 (Bunge Corp). All substrates were autoclaved for $1 \mathrm{~h}$ before use.

\subsection{Culture conditions}

The PR4 strain (Komukai-Nakamura et al., 1996) was obtained from the Japanese culture collection (NBRC 100887, NITE). The cells were grown in $100 \mathrm{~mL}$ flasks containing either $20 \mathrm{~mL}$ of minimal salt medium (Kis et al., 2013) (shortly, MSM: $0.68 \mathrm{~g} \mathrm{~L}^{-1} \mathrm{KH}_{2} \mathrm{PO}_{4}$; $0.87 \mathrm{~g} \mathrm{~L}^{-1} \mathrm{~K}_{2} \mathrm{HPO}_{4} ; 0.58 \mathrm{~g} \mathrm{~L}^{-1} \mathrm{NaCl} ; 0.125 \mathrm{~g} \mathrm{~L}^{-1} \mathrm{MgSO}_{4} \times 7 \mathrm{H}_{2} \mathrm{O}$; $0.044 \mathrm{~g} \mathrm{~L}^{-1} \mathrm{CaCl}_{2} \times 2 \mathrm{H}_{2} \mathrm{O} ; 0.0012 \mathrm{~g} \mathrm{~L}^{-1} \mathrm{NH}_{4} \mathrm{NO}_{3} ; 0.014 \mathrm{~g} \mathrm{~L}^{-1} \mathrm{FeSO}_{4}$ complexed with EDTA; $2 \mathrm{~mL}$ of trace element solution $\left(0.1 \mathrm{~g} \mathrm{~L}^{-1}\right.$ $\mathrm{ZnSO}_{4} \times 7 \mathrm{H}_{2} \mathrm{O} ; 0.03 \mathrm{~g} \mathrm{~L}^{-1} \mathrm{MnCl}_{2} \times 7 \mathrm{H}_{2} \mathrm{O} ; 0.3 \mathrm{~g} \mathrm{~L}^{-1} \mathrm{H}_{3} \mathrm{BO}_{4} ; 0.2 \mathrm{~g} \mathrm{~L}^{-1}$ $\mathrm{CoCl}_{2} \times 6 \mathrm{H}_{2} \mathrm{O} ; 0.01 \mathrm{~g} \mathrm{~L}^{-1} \mathrm{CuCl}_{2} \times 2 \mathrm{H}_{2} \mathrm{O} ; 0.02 \mathrm{~g} \mathrm{~L}^{-1} \mathrm{NiCl}_{2} \times 6 \mathrm{H}_{2} \mathrm{O}$; $0.03 \mathrm{~g} \mathrm{~L}^{-1} \mathrm{NaMoO}_{4} \times 6 \mathrm{H}_{2} \mathrm{O}$ )) or modified minimal salt medium containing $10.08 \mathrm{~g} \mathrm{~L}^{-1} \mathrm{NaHCO}_{3}$ (CMSM). The concentration of each substrate (pig lard, poultry fat, butter, margarine and vegetable oil) was $1 \%\left(\mathrm{~m} \mathrm{v}^{-1}\right)$ unless otherwise indicated. All samples were inoculated with $1 \%\left(\mathrm{v} \mathrm{v}^{-1}\right)$ of starter culture $\left(\mathrm{OD}_{600}=1.0\right)$ grown in Luria Broth (LB) medium (10 $\mathrm{g} \mathrm{L}^{-1}$ tryptone, $5 \mathrm{~g} \mathrm{~L}^{-1}$ yeast extract, $10 \mathrm{~g} \mathrm{~L}^{-1} \mathrm{NaCl}$ ). Before inoculation, the starter culture was centrifuged $\left(13,000 \mathrm{rpm}, 10 \mathrm{~min}, 4^{\circ} \mathrm{C}\right)$ and washed twice in physiological salt solution to prevent the transfer of the organic compounds of LB into the fresh media. In the control samples, bacteria were omitted. In each case, the samples were incubated in a rotary shaker $\left(150 \mathrm{rpm}\right.$ at $25^{\circ} \mathrm{C}$ ) for at least a week. Data from three independent experiments were collected and analyzed.

\subsection{Lipase activity assays}

The agar plate assay of Rajan et al. (2011) was used to visualize lipase activity. Tween 20 (Sigma-Aldrich) was an adequate substrate for simple and fast detection of microbial lipolytic activity on agar plate. White-like precipitate appears around the colony having lipase activity (Nagarajan et al., 2014).

\subsection{Analytic methods}

\subsubsection{Respiration activity}

Oxygen content of the headspace was measured by Agilent 6890 gas chromatograph equipped with a HP-MOLESIEVE column ( $30 \mathrm{~m} \times 0.53 \mathrm{~mm}$ i.d. $\times 0.25 \mu \mathrm{m}$ ) and a thermal conductivity detector (TCD). The injector was kept at $150^{\circ} \mathrm{C}$, while the oven temperature was adjusted to $60^{\circ} \mathrm{C}$. The injector was in splitless mode and nitrogen was used as carrier gas.

For the carbon dioxide measurements, Shimadzu GC-2010 gas chromatograph equipped with a TCD and HP-PlotQ column $(30 \mathrm{~m} \times 0.53$ i.d. $\times 0.25 \mu \mathrm{m}$ ) was used. The temperature of the injector and oven were $200^{\circ} \mathrm{C}$ and $90^{\circ} \mathrm{C}$, respectively. Samples of $50 \mu \mathrm{L}$ were injected via a split injection port at a split ratio of $0.5: 1$. Carrier gas was nitrogen at a flow rate of $63.8 \mathrm{~mL} / \mathrm{min}$.

\subsubsection{Analytics of animal fats}

In order to get methyl esters of poultry fat and pig lard, whole 
cultures were extracted with $7 \mathrm{~mL}$ chloroform. The bottles were shaken for $2 \mathrm{~h}$ at $25^{\circ} \mathrm{C}$ in a rotary shaker at $150 \mathrm{rpm}$. The organic phase was transferred into $10 \mathrm{~mL}$ Hypo-Vials then chloroform was evaporated using a Savant Speed-Vac Concentrator. A mixture composed of $90 \%$ methanol and $10 \%$ sulfuric acid solution ( $2 \mathrm{~mL}$ ) was added to each sample. Hypo-Vials were sealed with PTFE septa and samples were incubated at $100{ }^{\circ} \mathrm{C}$ for $210 \mathrm{~min}$ and stirred in every half hour, After the samples cooled down to room temperature, $2 \mathrm{~mL}$ of deionized water and $1 \mathrm{~mL}$ of chloroform were added. In order to extract fatty acid methyl esters, each sample was stirred vigorously for $2 \mathrm{~min}$. From the organic phase, $10 \mu \mathrm{L}$ aliquot was transferred into a $0.3 \mathrm{~mL}$ interlock crimp top vial and diluted with $990 \mu \mathrm{L}$ chloroform and stored at $-80{ }^{\circ} \mathrm{C}$ till further use. In each independent experiment, standards of $10 \mathrm{mg}, 50 \mathrm{mg}, 100 \mathrm{mg}$, $150 \mathrm{mg}$ and $200 \mathrm{mg}$ pig lard and poultry fat were also prepared and methyl esters were created; the analyses were always calibrated.

An Agilent 6890 gas chromatograph equipped with HP-Ultra-2 column $(25 \mathrm{~m} \times 0.2 \mathrm{~mm} \times 33 \mu \mathrm{m})$ and flame ionization detector (FID) was used for measuring methyl esters. $1 \mu \mathrm{L}$ sample was injected with an Agilent 7683 autosampler. Inlet was set in split mode with a split ratio of 30:1. Carrier gas was $\mathrm{H}_{2}$ (purity: 5.0). Initial oven temperature was $90^{\circ} \mathrm{C}$ then the following heating profile was used: heating to $120^{\circ} \mathrm{C}$ at a rate of $30^{\circ} \mathrm{C} \mathrm{min}{ }^{-1}$, then to $210^{\circ} \mathrm{C}$ at $10^{\circ} \mathrm{C} \mathrm{min}^{-1}, 210^{\circ} \mathrm{C}$ for $2 \mathrm{~min}$, heating to $280^{\circ} \mathrm{C}$ with a $50^{\circ} \mathrm{C} \mathrm{min}{ }^{-1}$ heating rate. In order to identify the compounds corresponding to the peaks, the samples were split between FID and an Agilent 5975C mass spectrometer equipped with electron impact ionization cell and simple quadrupole ion analyzer. All relevant peak areas coming from the FID signal were summed and considered as fatty acid content of a sample. Fat concentrations were calculated from calibration curve. Peaks were identified from the mass spectra in the NIST08 Mass Spectral Library and the data obtained for saturated and unsaturated fatty acids were combined, respectively.

\subsubsection{Thin layer chromatography}

Thin layer chromatography was used for monitoring the lipid degradation. The cultures were grown (as above) for $0,2,4,5$ and 7 days and used for analyses. Cell free samples were used as negative controls. The samples were extracted with chloroform, the solvents were evaporated and the dried materials were suspended in hexane. TLC Silica gel $60 \mathrm{~F}_{254}$ (Merck: 1.05554.0001) was used for monitoring the degradation of animal fats (mobile phase: hexane:diethyl ether:acetic acid (70:28:2)) (Cipinytè et al., 2009). The spots were visualized with $1 \% \mathrm{KMnO}_{4}$.

\subsection{Analysis of data}

Each experiment carried out with 3 parallel samples was repeated using independent starters leading to 6 datasets. The yield of biodegradation was calculated by the following equation:

Bioconversion yield $(\%)=\left[\left(\right.\right.$ Fats $_{\text {control }}-$ Fats treatment $]$ Fat $\left.\left._{\text {control }}\right) \times 100\right]$. The fat concentrations were calculated according to the calibration mentioned above.

\section{Results and discussion}

\subsection{Detection of the lipase activity}

Lipase genes could be recognized in the genome of PR4 (Sekine et al., 2006), thus we assumed that the strain could utilize greasy hydrophobic wastes. The lipase activity of the cells was qualitatively assayed. The lipase hydrolyzes Tween or fatty acids of polyoxyethylene sorbitan into free fatty acids which eventually bind to calcium salt included in the agar plate (see Materials and methods).
Thus, white crystal-salt like precipitates appear around the bacteria colony. Fig. 1 clearly shows a visible zone formed due to the intensive lipase activity of the PR4 strain.

\subsection{Preliminary biodegradation experiments with animal fats, vegetable oil, butter and margarine}

First, the PR4 strain was shown to use oxygen and evolve $\mathrm{CO}_{2}$ when either pig lard or poultry fat was provided as sole carbon and energy source (Fig. 2). It can be seen, that both $\mathrm{O}_{2}$ consumption (Fig. $2 \mathrm{~A}$ ) and $\mathrm{CO}_{2}$ evolution (Fig. 2 B) start immediately and $\mathrm{O}_{2}$ is completely taken up within three days. The biodegradation capacity of the strain was also tested on other substrates, such as butter, margarine and vegetable oil (VO, sunflower oil). From the results illustrated in Fig. 2, it was concluded that the PR4 strain could utilize VO, butter and margarine. The oxygen utilization of this strain was fast in the case of VO, oxygen was completely consumed within 3-4 days. The time dependent oxygen concentration profile of margarine was similar to that of VO, but in the experiments with butter, the oxygen consumption was completed only after a week.

PR4 strain was able to utilize all substrates tested but the efficiencies and time dependence varied with the substrates (Fig. 2). In the next sections, we focus on the biodegradation of pig lard and poultry fat.

\subsection{Monitoring the consumption of animal fats}

In the following experiments, fat consumption was monitored by GC-MS and TLC analysis.

Fatty acids were analyzed as their methyl-ester (FAME) derivatives by GC-MS. Four large peaks were separated on the chromatogram in both cases. They were assigned to methylated palmitoleic acid, palmitic acid, oleic + linoleic acid and stearic acid. Small amount of methyl-myristic acid was also present in both samples. The ratio of the various fatty acids in pig lard and poultry fats corresponded to the data of USDA (see 2.1 section). In pig lard, four other minor FAME peaks could be detected, but their amount was unimportant.

In a preliminary study, the efficiency of fat biodegradation in flasks containing MSM ( $\mathrm{pH}=6.8$ ) was monitored by GC-MS. After a week $18 \%$ (poultry fat) and $21 \%$ (pig lard) conversion yields were obtained. Since oxygen was not completely consumed, oxygen might not be the limiting factor. However, the $\mathrm{pH}$ of the media dropped to $\mathrm{pH}=4.0$ in 2 days (data not shown) which might

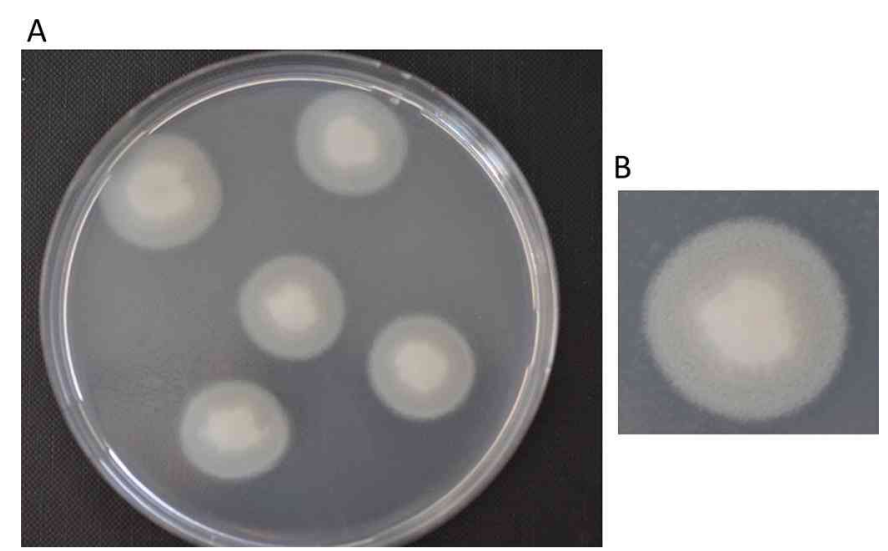

Fig. 1. Agar plate assay for lipase activity. The calcium salts of fatty acids appeared around the colonies of PR4 (A). One selected colony with calcium fatty acid salt ring is zoomed in (B). 
A

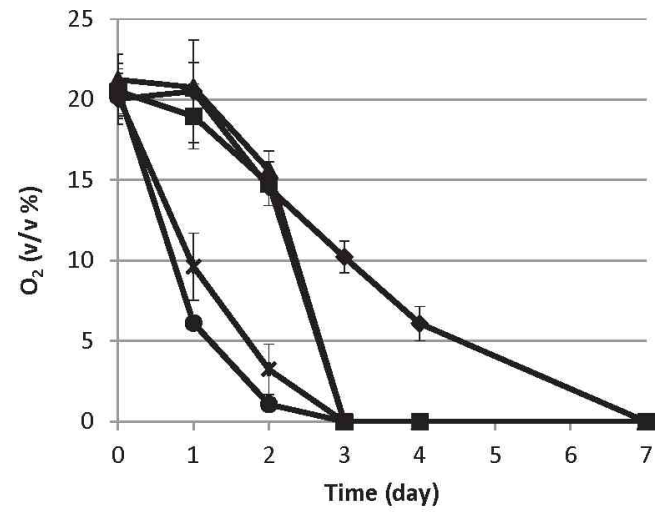

B

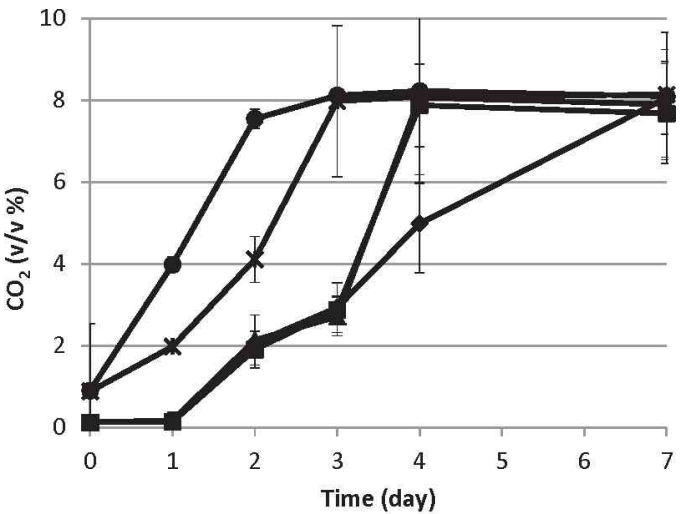

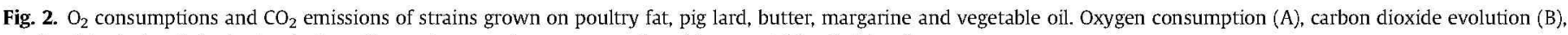
poultry fat: circle, pig lard: star, butter: diamond, margarine: square and cooking vegetable oil: triangle.

potentially block the metabolism of the cells. Additionally, the intermediate products of fermentation might also diminish the activity of the cells. Replacing the "used" medium with fresh one after two days led to a slight increase in the degradation efficiency of poultry fat (29\%), while the utilization of pig lard (10\%) remained practically the same as before. Therefore, the low yield could not be explained by product inhibition.

Next, the effect of the initial $\mathrm{pH}$ of the media was tested. Varying the initial pH of the MSM between 6.0 and 9.0 showed that the PR4 strain could degrade fats with the highest conversion: the yield was better than $80 \%(\mathrm{pH}=8.5)$ for poultry fat and around $70 \%$ for pig lard ( $\mathrm{pH}=8.0$ ) (Fig. $3 \mathrm{~A}, \mathrm{~B}$ ). The $\mathrm{pH}$ also dropped in each case suggesting that a) there was an intensive acid production and b) the buffering capacity of the medium was not enough. From these data, $\mathrm{pH}$ seemed to be a critical parameter of decomposition which must be kept at or near to the optimal value. It might be solved by either

A

Poultry fat

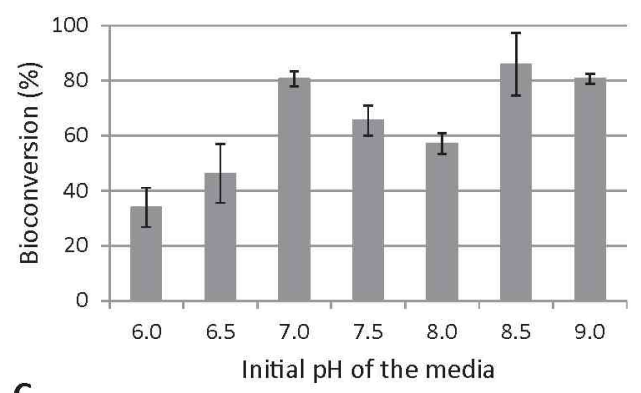

C

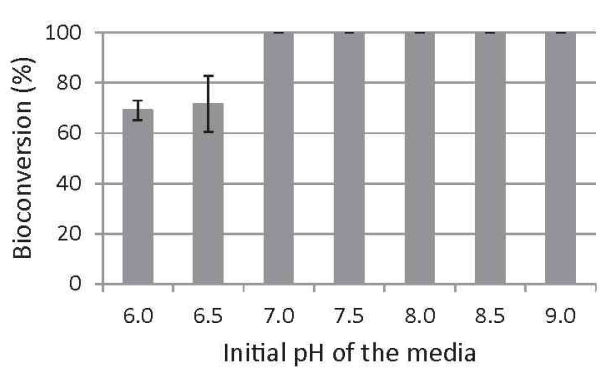

controlling the $\mathrm{pH}$ during fermentation or by increasing the buffering capacity of the medium. Since, the $\mathrm{pH}$ cannot be easily controlled during in situ applications, the $\mathrm{pH}$ stabilization was aimed by supplementing the MSM with $\mathrm{NaHCO}_{3}$.

\subsection{Optimization of the fat biodegradation conditions}

In order to increase the efficacy of the biodegradation of fats by $R$. erythropolis PR4, the previously used MSM was supplemented with various buffers at various concentrations. Finally, carbonate as a cheap material was chosen and the initial $\mathrm{pH}$ value of the fermentations was adjusted between 6.0 and 9.5.

Carbonate supplementation (CMSM media) dramatically enhanced the conversion yield using both types of fats (Fig. 3C, D). Conversion of fats was measured by fatty acids methyl esters with GC-MS (see Materials and methods 2.4.2.) Biodegradation of
B
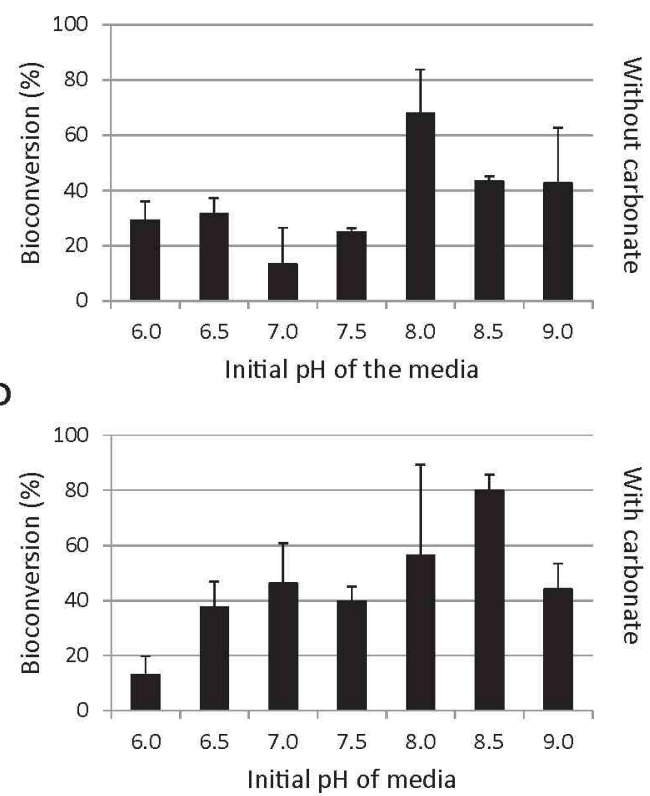

Fig. 3. Bioconversion (\%) of poultry fat ( $A$ and $C$ ) and pig lard (B and D) at various initial pH of the MSM medium (A and B) and carbonate supplemented MSM medium (C and D) after a week. The fat concentration was measured by GC-MS (see Materials and methods). 
poultry fat was complete at $\mathrm{pH}=7.0$ and above. Almost $80 \%$ of the initial pig lard content was eliminated from the cultures at $\mathbf{p H}=8.5$ in a week. The involvement of carbonate resulted in a quite good consumption of poultry fat $(72 \%)$ at lower $\mathrm{pH}(\mathrm{pH}=6.0)$, as well. Additionally, the initial $\mathrm{pH}$ of the CMSM medium of the samples remained remarkably stable during the fermentations. These data suggested that addition of carbonates could dramatically improve the bioconversion of animal fats likely due to its $\mathrm{pH}$ stabilizing effect. The $\mathrm{pH}$ optimum for pig lard degradation was narrow with a relatively sharp maximum in the efficacy at $\mathrm{pH}=\mathbf{8 . 5}$.

\subsection{Time dependence of poultry fat and pig lard consumption}

After establishing a good medium for degradation of fats in laboratory conditions, the temporal changes of the fat contents were monitored.

In the experiments above, the optimal $\mathrm{pH}$ range for biodegradation was $\mathrm{pH}=7.0-9.0$ in case of poultry fat, while highest yield was achieved at $\mathrm{pH}=8.5$ for pig lard. The consumption of these substrates was followed in time at these initial pH values in CMSM media (Fig. 4). Longer time was required for consumption of pig fat likely due to higher viscosity of pig lard. Nevertheless, it could be concluded that the PR4 strain could efficiently convert both types of fats within a reasonable time.

Mass spectrometric analysis was performed to follow the degradation of lipids with saturated and unsaturated fatty acids. The degradation curves illustrated in Fig. 5 were quite similar for fats containing either saturated and unsaturated fatty acids for both substrates (it is also true for the 5 individual fatty acid components identified). The degradation of poultry fat had a lag phase of around $36 \mathrm{~h}$ but the substrate was completely decomposed within four days. The conversion of pig lard started immediately, but was incomplete coinciding with the data of Fig. 4.

The biodegradation processes were followed by TLC analysis (data not shown). In the case of poultry fat, in consistency with the GC-MS analysis, the triglycerides disappeared from the medium and much less amount of fatty acids appeared as intermediates. Using pig lard, the amount of the triglycerides also decreased in time but the degradation was slower as compared to the picture obtained for poultry fats.

\subsection{Comparison of biodegradation performance of our and other strains}

There are a number of studies for degradation of lipids and/or removal of animal fats from various wastes (Wakelin and Forster,

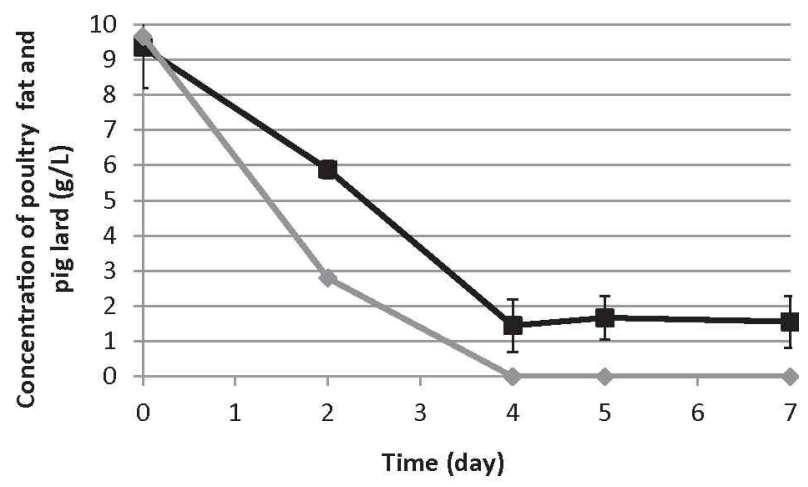

Fig. 4. Biodegradation kinetics of poultry fat and pig lard in CMSM. Poultry fat: gray and diamond; Pig lard: black and square. Methyl-ester derivatives of fatty acids were quantified by GC-MS (for details, see Materials and methods).

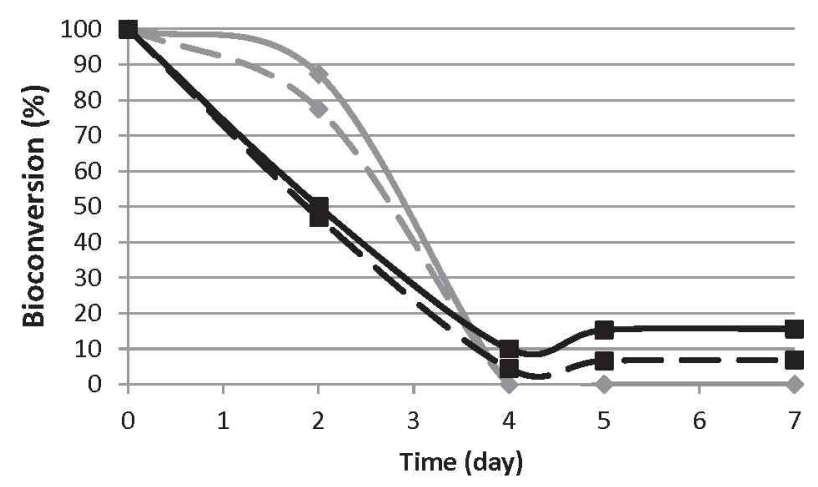

Fig. 5. Bioconversion (\%) of saturated fatty acid (continuous line) and unsaturated fatty acid (broken line) in CMSM. Poultry fat: gray and diamond; Pig lard: black and square.

1998; Keenan and Sabelnikov, 2000; Mongkolthanaruk and Dharmsthiti, 2002; Sugimori et al., 2002; Prasad and Manjunath, 2011; Affandi et al., 2014). However, none of them studied the capacity of any Rhodococcus strain for this activity. In a recent study, Prasad and Manjunath (2011) compared the potential of six individual strains (three Bacillus species, one Serratia, one Pseudomonas and one Staphylococcus strain) for degradation of fatcontaining wastes such as vegetable oils and dairy wastes. In their experiments, a Pseudomonas aeruginosa and a consortium had the best performance for decomposition of lipids: almost complete removal of the contaminant could be achieved within a 12 days period utilizing fluid lipids in $25 \mathrm{~g} \mathrm{~L}^{-1}$ concentration.

In our study, all substrates were used in $10 \mathrm{~g} \mathrm{~L}^{-1}$ concentration and vegetable oil seemed to be an "easy" substrate for $R$. erythropolis PR4. Moreover, efficient removal of the other lipids, such as poultry fat or pig lard could be achieved within 4-7 days after an optimization of the processes.

\section{Conclusion}

The $R$. erythropolis PR4 strain was successfully applied for degradation of various hydrophobic kitchen wastes including pig lard, poultry fats, margarine, butter and vegetable oil. The performance of our strain was compared to those published in the literature. Although, the systems are not fully comparable, these data are strong indicators that the PR4 strain is a promising candidate for time-intensive removal/refinery of fat-containing wastes either individually and/or in a properly designed consortium for bioremediation or other purposes.

\section{Acknowledgments}

This research was realized in the frames of TÁMOP 4.2.4.A/2-111-2012-001 "National Excellence Program- Elaborating and operating an inland student and researcher personal support system convergence program" The project was subsidized by the European Union and cofinanced by the European Social Fund." "The Project is supported by the European Union and co-financed by the European Social Fund (grant agreement no. TÁMOP-4.1.1.C-12/1/KONV-20120012)".

\section{References}

Affandi, I.E., Suratman, N.H., Abdullah, S., Ahmad, W.A.A., Zakaria, Z.A., 2014. Degradation of oil and grease from high-strength industrial effluents using locally isolated aerobic biosurfactant-producing bacteria. Int. Biodeterior. Biodegr. 95, 33-40.

Banat, I.M., Franzetti, A., Gandolfi, I., Bestetti, G., Martinotti, M.G., Fracchia, L., Smyth, T.J., Marchant, R., 2010. Microbial biosurfactants production, 
applications and future potential. Appl. Microbiol. Biotechnol. 87, 427-444.

Becker, P. Köster, D, Popov, MN., Markossian, S., Antranikian, G., Märkl, H., 1999. The biodegradation of olive oil and the treatment of lipid-rich wool scouring wastewater under aerobic thermophilic conditions. Water Res. 33, 653-660.

Bell, K.S., Philp, J.C., Aw, D.W.J., Christofi, N., 1998. The genus Rhodococcus. J. Appl. Microbiol. 85, 195-210.

Bitman, J., 1976. Status report on the alteration of fatty acids and sterol composition in lipids in meat, milk, and eggs in national research council. Fat content and composition of animal products. In: Proceedings of a Symposium. The Nationa Academies Press, Washington, DC, ISBN 0-309-02440-4, pp. 200-237.

Chipasa, K.B., Mędrzycka, K., 2006. Behavior of lipids in biological wastewater treatment processes. J. Ind. Microbiol. Biotechnol. 33, 635-645.

Cipinytè, V., Grigiskis, S., Baskys, E., 2009. Selection of fat-degrading microorganisms for the treatment of lipid-contaminated environment. Biologija 55, 84-92.

De Carvalho, C.C.C.R., Da Fonseca, M.M.R., 2005a. Degradation of hydrocarbons and alcohols at different temperatures and salinities by Rhodococcus erythropolis DCL14. FEMS Microbiol. Ecol. 51, 389-399.

De Carvalho, C.C.C.R., Da Fonseca, M.M.R., 2005b. The remarkable Rhodococcus erythropolis. Appl. Microbiol. Biotechnol. 67, 715-726.

Fukase, T., Kawatsu, M., Yayoshi, K. and Mitome, R. (1993) Treatment of fat and oil containing waste water, Japanese Patent JP05154464.

Hamada, T., Sameshima, Y., Honda, K., Omasa, T., Kato, I., Ohtake, H., 2008. A comparison of various methods to predict bacterial predilection for organic solvents used as reaction media. I. Biosci. Bioeng. 106 (4), 357-362.

He, X., Iasmin, M., Dean, L.O., Lappi, S.E., Ducoste, I.I, de los Reyes, F.L., 2011. Evidence for fat, oil, and grease (FOG) deposit formation mechanisms in sewer lines. Environ. Sci. Technol. 45, 4385-4391.

He, X., Osborne, I., de los Reyes, F.L., 2012. Physico-chemical characterization of grease interceptors with and without biological product addition. Water Environ. Res. 84, 195-201.

He, X., de los Reyes, F.L., Leming, M.L., Dean, L.O., Lappi, S.E., Ducoste, I.J., 2013. Mechanisms of fat, oil and grease (FOG) deposit formation in sewer lines. Water Res. 47, 4451-4459.

Jaeger, K.-E., Eggert, T., 2002. Lipases for biotechnology. Curr. Opin. Biotechnol. 13, 390-397.

Keenan, D., Sabelnikov, A., 2000. Biological augmentation eliminates grease and oil in bakery wastewater. Water Environ. Res. 72, 141-146.

Kis, Á., Laczi, K., Hajdú, A., Szilágyi, Á., Rákhely, G., Perei, K., 2013. Efficient removal of unctuous wastes from wastewater. Int. J. Biosci. Biochem. Bioinform. 3 , 395-397.

Komukai-Nakamura, S., Sugiura, K., Yamauchi-Inomata, Y., Toki, H., Vankateswaran, K., Yamamoto, S., Tanaka, H., Harayama, S., 1996. Construction of bacterial consortia that degrade Arabian light crude oil. J. Ferment Bioeng. 82 (6), 570-574.

Lee, E.-H., Kim, I., Cho, K.-S., Ahn, Y.G., Hwang, G.-S., 2010. Degradation of hexane and other recalcitrant hydrocarbons by a novel isolate Rhodococcus sp. EH831. Environ. Sci. Pollut. Res. Int. 17, 64-77.

Lefebvre, X., Paul, E., Mauret, M., Baptiste, P., Capdeville, B., 1998. Kinetic characterization of saponified domestic lipid residues aerobic biodegradation. Water Res. 32, 3031-3038.

Mari, I., Ehaliotis, C., Kotsou, M., Balis, C., Georgakakis, D., 2003. Respiration profiles in monitoring the composting of by-products from the olive oil agro-industry. Bioresour. Technol. 87, 331-336.

Mongkolthanaruk, W., Dharmsthiti, S., 2002. Biodegradation of lipid-rich wastewater by a mixed bacterial consortium. Int. Biodeterior. Biodegr. 50, 101-105.

Nagarajan, I., Nawawi, N.M., Ibrahim, A.L., 2014. Rhodococcus UKMP-5M, an endogenous lipase producing actinomycete from Peninsular Malaysia. Biologia $69,123-132$.

Pandey, A., Benjamin, S., Soccol, C.R., Nigam, P., Krieger, N., Soccol, V.T., 1999. The realm of microbial lipases in biotechnology. Biotechnol. Appl. Biochem. 29, $119-131$.

Prasad, M.P., Manjunath, K., 2011. Comparative study on biodegradation of lipid-rich wastewater using lipase producing bacterial species. Indian J. Biotechnol. 10 121-124.

Rajan, A., Kumar, D.R.S., Nair, A.I., 2011. Isolation of a novel alkaline lipase producing fungus, Aspergillus fumigatus MTCC 9657 from aged and crude rice bran oil and quantification by HPTLC. Int. I. Biol. Chem. 5, 116-126.

Ruggieri, L., Artola, A., Gea, T., Sánchez, A., 2008. Biodegradation of animal fats in a co-composting process with wastewater sludge. Int. Biodeterior. Biodegr. 62 , 297-303.

Saatci, Y., Arslan, E.I., Konar, V., 2003. Removal of total lipids and fatty acids from sunflower oil factory effluent by UASB reactor. Bioresour. Technol. 87, 269-272.

Sekine, M., Tanikawa, S., Omata, S., Saito, M., Fujisawa, T., Tsukatani, N., Tajima, T. Sekigawa, T., Kosugi, H., Matsuo, Y., Nishiko, R., Imamura, K., Ito, M., Narita, H. Tago, S., Fujita, N., Harayama, S., 2006. Sequence analysis of three plasmids harboured in Rhodococcus erythropolis strain PR4. Environ. Microbiol. 8 (2), $334-346$.

Serikovna, S.Z., Serikovich, K.S., Sakenovna, A.S., Murzakhmetovich, S.S. Khamitovich, A.K., 2013. Screening of lipid degrading microorganisms for wastewater treatment. Malays. I. Microbiol. 9, 219-226.

Sugimori, D., Nakamura, M., Mihara, Y., 2002. Microbial degradation of lipid by Acinetobacter sp. strain SOD-1. Biosci. Biotechnol. Biochem. 66, 1579-1582.

Tan, K.H., Gill, C.O., 1985. Batch growth of Saccharomycopsis lipolytica on animal fats. Appl. Microbiol. Biotechnol. 21, 292-298.

Urai, M. Yoshizaki, H., Anzai, H., Ogihara, I. Iwabuchi, N., Harayama, S. Sunairi, M. Nakajima, M., 2007a. Structural analysis of mucoidan, an acidic extracellular polysaccharide produced by a pristane-assimilating marine bacterium, Rhodococcus erythropolis PR4. Carbohydr. Res. 342 (7), 927-932, 21.

Urai, M., Yoshizaki, H., Anzai, H., Ogihara, J., Iwabuchi, N., Harayama, S., Sunairi, M., Nakajima, M., 2007b. Structural analysis of an acidic, fatty acid ester-bonded extracellular polysaccharide produced by a pristane-assimilating marine bacterium, Rhodococcus erythropolis PR4. Carbohydr. Res. 342 (7), 933-942, 21.

Wakelin, N.G., Forster, C.F., 1997. An investigation into microbial removal of fats, oils and greases. Bioresour. Technol. 59, 37-43.

Wakelin, N.G., Forster, C.F., 1998. The aerobic treatment of grease-containing fast food restaurant wastewaters. Process Saf. Environ. Prot. 76, 55-61. 